\title{
Organizational and Functional Modeling of Business Processes for Management of the Development Project Efficiency
}

\author{
Elena Soboleva ${ }^{1,}$ \\ ${ }^{1}$ Moscow State University of Civil Engineering,26, Yaroslavskoye shosse, Moscow,129337, Russia
}

\begin{abstract}
The article is devoted to development project management issues in the current economic situation in Russia, to the construction industry, to the problems of development projects implementation in Russia and to the impact of the quality of projects in the construction industry, to assessment of the impact of external project environment on the effectiveness of project activities in crisis, as well as to project management quality. A methodological approach to qualitative management of development project efficiency. Actualized methodology interaction of individual units of the implementation process and the development of a development project by construction of houses. The main stages of the development project. The analysis of the current economic situation in Russia.
\end{abstract}

\section{Introduction}

Today, under crisis conditions in the Russian economy, the downward trend in imports of a number of building materials is proof of productivity loss in the construction industry due to a range of factors of the economic crisis in the country:

1. A decrease in purchasing power of the population by 7.5\%, only in August 2016 and a decrease in demand for the products of the construction industry - housing;

2 . An increase in the cost of construction products;

3. Bankruptcy of the majority of construction companies;

4. A decline in productivity and related industries, including the production of construction materials and equipment.

In the current economic situation a relevant and necessary for the developer solution is to search for effective management and regulation of the economic and financial results of the project, and to search for a sustainable status of the project and its development; as a result qualitative transformation of property will be achieved, which defines the subject and nature of development. One should also pay attention to the problems of innovation in construction and import substitution under sanctions and manufacture crisis [1].

\section{Experimental part}

*Corresponding author: alenas_06@mail.ru 
Programmable and planned positive development project result will be effective only on the strict condition of operational control of the current project situation and on condition of a constant analysis of achieving the projected results at the start of development. A probabilistic approach is not relevant in this case. Only exact economic calculations of all project processes by the proposed method by establishing an economic and financial model of the development project, which serves as a tool for monitoring and analyzing the implementation of the project with the help of evaluating the current project efficiency and sustainability. Only provided a good governance of development project it is possible to achieve the planned results, herewith the management of the project should link various areas of knowledge and relevant technological processes [2]. The developer can influence the outcome of the project, objectives, quality, time and cost of execution, only by choosing technologies, composition, performance and resource assignment to execution of various activities and tasks of the development project.

Current efficiency of development projects is an important economic characteristic, which helps to quickly assess the future performance of using the current correlations and making urgent changes to the project management, depending on the current situation both on the macro and micro levels.

Analysis and control of the current efficiency of development projects require tools for the analyzing and developing the project development management methods. A project management system in the development field is to be understood as an absolutely productive system state (project state), in which there is the possibility of monitoring, analysis, control and quality management of the ability to achieve the economical performance of the project and the current overall efficiency at the optimum combination of economical, financial, organizational and functional, technical and innovative features of the project. To achieve effect as a project management methodology economical and organizational modeling is necessary. Such business-modeling of the development project economics is advisable to be carries out on the basis of the business processes matrix [3].

As a business process matrix a table of analysis of the interaction of processes is used, allowing to identify the most important business processes, to establish their relationship, to determine the outcome of each process and to assess the impact of processes on the project as a whole. Operational management of this system solves the problem of drawing up and further operation of the matrix. Business process structuring for the development project through a business process matrix allows you to make all the operations and objectives transparent and clear, which lets you analyze processes, understand the frontline workers, control the execution of tasks and find problems on time that can lead to poor results of a specific process or subtasks, as well as of the overall efficiency of the development project being implemented. This should be dealt with directly by the developer himself. The business process matrix allows the developer to understand the details of the interaction between the various project participants at each stage of the project. Therefore, such a process approach greatly simplifies the adaptation of possible replacements of the participants along with its implementation depending on the length (duration of the project) and reduces the dependence of the project team on the human factor [4]. This approach facilitates the management of operating expenses. The life cycle of a development project is divided into four main components of the organizational and functional matrix (OFM): strategy, planning, actual data collection, reporting and approval.

The matrix (OFM) is a closed cycle, which allows to take into account the terms of the complete cycle of a development project, regardless of its length and at all stages of the life cycle. Matrix is adapted to the long development project and is a working tool for short-, medium- and long-term projects. In the horizontal portion of the BP matrix (OFM) there is a time period of a calendar year, broken down by quarters, months and days. The implementation process is cyclical, therefore, business processes are applicable not only 
within one year, but also during the whole period of implementing and developing of a development project [5].

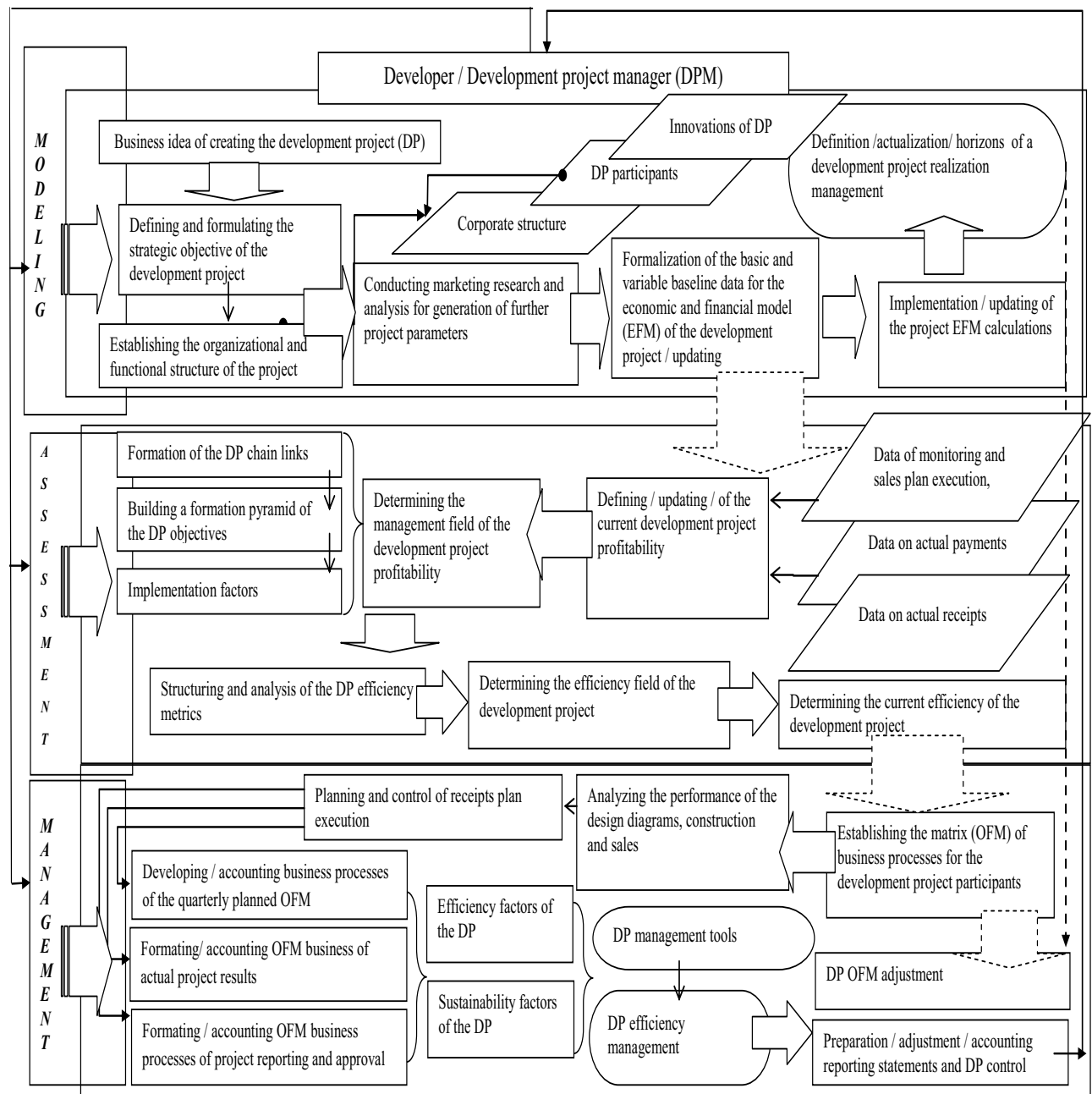

Fig. 1 Algorithm of the organizational and functional management of a development project

The vertical part of the BP (OFM) includes all structural responsible and controlling participants of the implementation business process. The main and the weighty task of organizational and functional business processes of the matrix is representation of the project development in the form of an "organism", where all processes are interconnected the input parameters of the following process-tasks depend on the previous task results, herewith all the basic and related processes are used to the extent of specification. The proposed instrument is recommended as the primary regulatory framework in the implementation of development projects, should be a guiding document for the participants of the project implemented since when failure of one process occurs, changes and risks of further project activities are visible immediately.

Thus, through the organization and management of business processes on the proposed matrix, the developer controls the efficiency of the implemented project in real estate, so from the functional point of view, the offered "matrix" method is called economic- 
organizational modeling of business processes of the performance management matrix of the development project and its sustainable development [6].

The result of the performed adjusted research in the field of development with reference to the current economic situation and with approbation on existing development projects is a real performance management scheme of development project by means of using the OFM - organizational and functional matrix of management business processes [7].

Scientific justification of the proposed format for the organizational and functional matrix (OFM) of business processes and methodology for implementation of development projects allows to manage the project effectively and to implement it in terms of any participants' number and, regardless of the duration of the project life cycle.

This is due to the fact that the modified and improved economic and organizational model (EOM) to the stages of the financial and economic modeling (FEM) based on structured in functional zoning of the business processes of the matrix (RPM) development project allows to accumulate the activities of the project participants and take into account all parties at its implementation, which will help to prevent risks and situational changes during the life cycle well-timed.

\section{Results}

Thus, the developer gets an opportunity to make the current assessment of the effectiveness of planned and actual data of the planned, as well as implemented development projects. Calculation and timely assessment of the current profitability of the development project show the maximum and minimum profitability zone, giving the developer project management tools.

Development is a professional business management of the investment and construction process, the point of which is to transform the property by complex influence in order to obtain benefits and achievements of the four kinds of the development projects efficiency (social, fiscal, commercial and economic) through an increase in the value of such an object [8].

Consequently, the proposed methodological approach to assessment and management of development projects can achieve the desired effect and the planned development of the whole development complex. Furthermore, regular use of the proposed method allows you to control the current situation in the implementation of a development project, to analyze its possible perspectives and to take stabilization measures timely.

\section{Discussion}

Creating an economic and financial model (EFM) for the proposed project at the stage of a business idea allows "to calculate" the idea in a certain way and to make the right decision when choosing a development project strategy at the earliest stage. EFM is the "conductor of result" for the developer at all stages of implementation and realization of the development project, because it is the art of a developer to understand how the market will react to specific changes in the real estate in the future [9].

Thus, having created an economic and financial model (EFM), the developer controls the current profitability of a development project through the organizational and functional matrix (OFM) and the economic and organizational modeling (EOM) business processes. Evaluating the efficiency by using the current profitability index allows the developer to define the current situation, monitor the implementation of plans and manage the prospects of the development project. 


\section{Conclusion}

Therefore, when assessing the current macro and micro situation and its impact on the economy as a whole and particularly considering the construction industry, today, the very complexity of the implementation of development projects should not be excluded. In today's recession in the commercial and residential real estate, in the absence of the necessary project management techniques the risk of failure and bankruptcy of the projects increases, which inevitably leads to an increase in price of real estate and to suspension of most projects. The consequence will be shortage of housing, socially and culturally important objects, as well as aging of the housing stock.

\section{References}

1. S. Bartel, G. Janssen. Tunnelling and Underground Space Technology, 55, 112-117 (2016)

2. J. Shaoul. Critical Perspectives on Accounting, 16(4), 441-471(2006)

3. C. Delmastro, E.Lavagno, L.Schranz. Tunnelling and Underground Space Technology,55, 103-111(2016)

4. V. Khmel, S. Zhao. IATSS Research,39, (2), 138-145(2016)

5. E.K. Chirkunova, E.E. Kireeva, A.D. Kornilova, J.S. Pschenichnikova. Procedia Engineering,153,112-117 (2016)

6. Li Yingjian, Yousif A. Abakr, Qiu Qi, You Xinkui, Zhou Jiping. Renewable and Sustainable Energy Reviews,59, 1195-1208(2016)

7. L. Kanapeckiene, A.Kaklauskas, E.KazimierasZavadskas, S.Raslanas. Expert Systems with Applications,38, (11), 14196-14207(2011)

8. S.V. Domnina, E.V. Savoskina, N.V. Shekhova. Procedia Engineering,153, 741-746 (2016)

9. V. Platon, S. Frone, A. Constantinescu. Economics and Finance, 8, 204-210 (2014) 